\title{
MODELING AND OPTMIZATION POWER REQUIREMENTS OF ACTIVE ACOUSTIC LOUVRES
}

\begin{abstract}
M. A. Maciel ${ }^{\mathrm{a}}$,
G. A. Zuffi ${ }^{\text {b }}$, and M. A. V. Duarte ${ }^{b}$

${ }^{a}$ Universidade Federal da Fronteira Sul. Av. Dom João Hoffmann, 313. Erechim - RS, Brazil marcela.maciel@uffs.edu.br

${ }^{\mathrm{b}}$ Universidade Federal de Uberlandia. Departamento de Engenharia Mecânica Av. João Naves De Ávila, 2121. Uberlândia - MG. Brazil. mvduarte@mecanica.ufu.br

ABSTRACT

The development of new technologies for ventilated facades is within the context of energy efficiency of buildings, including the compatibility of the dichotomy between natural ventilation and soundproofing in tropical countries . Given this perspective, this work proposes the application of techniques for active noise control in acoustic louvers . One limitation of the spread of technical active noise control in buildings is the energy inherent in the technique. Thus, the proposed system is based on the reduction of structural vibrations of the shutter blades by using piezoelectric actuators . The acoustic transmission loss and energy requirements for active shutters are investigated from numerical modeling. The results suggest their technical feasibility with superior soundproofing to $30 \mathrm{~dB}$ and power consumption less than $35 \mathrm{~W}$. Thus, the active noise control using piezoelectric actuators is presented as a promising technology, aligning soundproofing with low energy consumption

Type the text of the abstract here, Times New Roman, 9, lower case letters, justified paragraphs, 1.0 line spacing. The abstract should state the objectives, methodology and main conclusions in 200 to 300 words. No not divide into paragraphs.
\end{abstract}

Received: September 10, 2015 Revised: October 13, 2015 Accepted: November 09, 2015

Keywords: smart materials, energy efficiency, noise control

\section{NOMENCLATURE}

A is the area of the blade, $\left[\mathrm{m}^{2}\right]$;

c is the speed of sound, $[\mathrm{m} / \mathrm{s}]$;

$\mathrm{d}_{31}$ is the actuator piezoelectric constant [C/N];

$\mathrm{E}_{\mathrm{p}} \quad$ is the blade Young Modulus, [Pa ];

$\mathrm{E}_{\mathrm{pe}}$ is the piezoelectric actuator Young Modulus of the, [Pa ];

$\mathrm{h} \quad$ is the blade thickness, [m]

$\mathrm{I}_{\mathrm{m}} \mathrm{I}_{\mathrm{n}}$ are functions derived from the Rayleigh integral;

$\mathrm{L}_{\mathrm{x}} \quad$ is the blade length, [m];

$\mathrm{L}_{\mathrm{y}} \quad$ is the blade width, [m];

$\mathrm{m}, \mathrm{n}$ are modal indices.

$\mathrm{m}_{\mathrm{s}} \quad$ is the surface mass of the blade, $\left[\mathrm{kg} / \mathrm{m}^{2}\right]$;

$\mathrm{P}_{\mathrm{c}} \quad$ is the radiated acoustic pressure for acoustic louvre, $[\mathrm{Pa}]$;

$\mathrm{Pi}$ is the sound pressure incident on the blade, [Pa];

$\mathrm{P}_{\mathrm{n}} \quad$ is the radiated acoustic pressure for primary source, [Pa];

$\mathrm{P}_{\mathrm{t}} \quad$ is the total radiated acoustic pressure, [Pa];

$\mathrm{R}$ is the distance from the observation point to elemental source, [m]

$\mathrm{r} \quad$ is the distance from the observation point to the origin of the coordinate system, [m];

$\mathrm{t}$ is the thickness of the piezoelectric actuator, [m];

$\mathrm{V}$ is the input voltage to the actuator, [V];

$\mathrm{W}_{\mathrm{mn}}$ are the modal amplitude for the blade, [dimensionless];
$\mathrm{W}_{\mathrm{mn}, \mathrm{pzt}}$ are modal amplitude for the blade with piezoelectric actuators, [dimensionless]; $\mathrm{x}_{1} ; \mathrm{x}_{2} ; \mathrm{y}_{1} \mathrm{e} \mathrm{y}_{2}$ are the geometric coordinates of the piezoelectric actuator relative to blade, $[\mathrm{m}]$

\section{Greek symbols}

$\omega \quad$ is the frequency of external excitation, [rad/s] $\rho_{0} \quad$ is the density of the medium, [kg/m3];

$\gamma_{\mathrm{m}} ; \gamma_{\mathrm{n}}$ are the modal numbers of blade;

$\omega_{\mathrm{mn}}$ are the natural frequencies of vibration of the blade, [rad/s]

$\rho_{\mathrm{p}} \quad$ is the blade density, $[\mathrm{kg} / \mathrm{m} 3]$;

$v_{\mathrm{p}}$ is the blade Poisson's ratio, [dimensionless];

$v_{\mathrm{pe}}$ is the piezoelectric actuator Poisson's ratio [dimensionless].

\section{INTRODUCTION}

The active control technique is used to reduce noise or vibration using devices that supply power to the system. The term "active" is used in contrast to "passive", in which only the mechanisms of internal energy dissipation of materials are sufficient for significant noise attenuation. Utilizing the principle of destructive interference, the active control will the attenuation of noise generated by a primary source for the emission of a signal caused by a secondary source, the same amplitude and opposite phase. The basic components of active control systems are sensor elements used to capture the environmental or 
operational changes; actuators elements responsible for the adaptation system; and control algorithms, which determine the control actions to be performed by actuators, from the information acquired by the sensors.

The use of active noise control technique to increase the transmission loss at low frequencies is suggested by Salis et al. (2002), Naticchia and Carbonaria (2007). These techniques are presented as a useful field of application in ventilated widowns, given the need to overcome the limitations imposed by the overall performance in low attenuation below $15 \mathrm{~dB}$ frequency, as evidenced in passive strategies presented by Field and Fricke (1998), Viveiros and Gibbs (2003), Viegas (2009), Araujo (2010) and Oiticica (2010).

The application of the technique of active noise control in acoustic louvres makes use of piezoelectric materials attached to the blades. These materials have shown interesting results with intrinsic to the technology advantages such as: allow their use in complex geometries; can be used both as sensors and actuators; as well as allow its use under severe environmental conditions, due to its relative insensitivity to temperature. The piezoeletric materials develop an electric field when subjected to a force (or pressure), i.e, direct piezoelectric effect, and have a deformation when subjected to an electric field, i.e, inverse piezoelectric effect. Active acoustic louvers are used the inverse piezoelectric effect to reduce noise radiation by changing the structural behavior of the blades.

The use of piezoelectric actuators in systems for active noise control features like power consumption requirement for processing the input signal to the actuator in a suitable control signal. Thus, the requirements of electrical power is an important parameter in the design of active louvres. For optimum control conditions, the external force must be less than or equal to the block actuator force. Considering a condition of perfectly controlled structure, the displacement of the structure coupled with actuators should be null. Otherwise, additional forces are introduced contributing to the reduction of the total admittance of the actuator. In this case, the effectiveness of the control decreases, with a consequent reduction of power required.

Considering that is implicit to the concept of active noise control energy consumption, this paper presents the objective of modeling the energy demand for operation of acoustic louvers and accompanying acoustic efficiency.

\section{METHOD}

\section{Analytical modelling}

The modeling of the transmission loss of the active acoustic louvre is made for the system of isolated blades.

$$
\begin{gathered}
p_{t}=p_{c}+p_{n} \\
p_{c}(r, \theta, \phi)=K \sum_{m=1}^{\infty} \sum_{n=1}^{\infty} W_{m n, p z t} I_{m} I_{n} \\
p_{n}(r, \theta, \phi)=K \sum_{m=1}^{\infty} \sum_{n=1}^{\infty} W_{m n} I_{m} I_{n} \\
K=\frac{-\omega^{2} \rho_{0} e}{2 \pi R}\left(t-\frac{r}{c}\right) \\
W_{m n}=\frac{P_{i} I_{m} I_{n}}{\frac{L_{x} L_{y}}{4} \rho_{p} h\left(\omega_{m n}^{2}-\omega^{2}\right)}
\end{gathered}
$$

The total radiated acoustic pressure of the blades given by Eq. (1) can be obtained by the superposition principle, i.e, by the action of thin plate instrumented with piezoelectric actuators and the primary source, as Eq. (2) and Eq. (3), respectively, and the parameter $\mathrm{K}$ is given by Eq. (4). So, the modal amplitudes of the blade are given by Eq. (5):

The geometric model of active louvre are presented in Fig.1, with the piezoelectric actuators centralized in the blade.

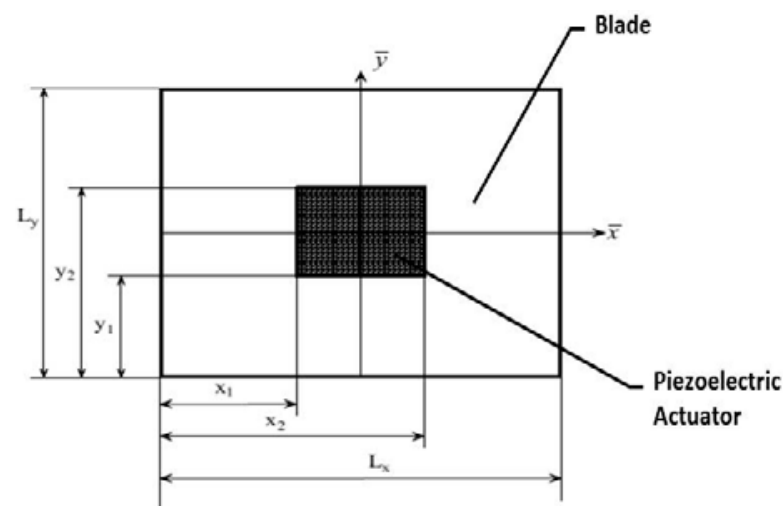

Figure 1. Placement of piezoelectric actuators in the blade.

$$
\begin{gathered}
\bar{W}_{m n}=\frac{4 C_{0 d_{31} \bar{V}}}{t A m_{S}\left(\omega_{m n}^{2}-\omega^{2}\right)} \\
\left\{-\left(\frac{\gamma_{m}^{2}+\gamma_{n}^{2}}{\gamma_{m} \gamma_{n}}\right)\left[\cos \left(\gamma_{m} x_{1}\right)-\cos \left(\gamma_{m} x_{2}\right)\right]\right. \\
\left.\left[\cos \left(\gamma_{\mathrm{n}} \mathrm{y}_{1}\right)-\cos \left(\gamma_{\mathrm{n}} \mathrm{y}_{2}\right)\right]\right\} \\
\mathrm{C}_{0}=-\mathrm{E}_{\mathrm{p}} \frac{\left(1+\mathrm{v}_{\mathrm{pe}}\right) \mathrm{P}}{\left(1-\mathrm{v}_{\mathrm{pe}}\right)\left[1+\mathrm{v}_{\mathrm{p}}-\left(1+\mathrm{v}_{\mathrm{pe}}\right) \mathrm{P}\right]} \frac{2}{3} \mathrm{~h}^{2}
\end{gathered}
$$




$$
\begin{gathered}
\mathrm{P}=-\mathrm{K} \frac{\mathrm{E}_{\mathrm{pe}}\left(1-\mathrm{v}_{\mathrm{p}}^{2}\right)}{\mathrm{E}_{\mathrm{p}}\left(1-\mathrm{v}_{\mathrm{pe}}^{2}\right)} \\
\mathrm{K}=\frac{3 \mathrm{th}(2 \mathrm{~h}+\mathrm{t})}{2\left(\mathrm{~h}^{3}+\mathrm{t}^{3}\right)+3 \mathrm{ht}^{2}} \\
\gamma_{\mathrm{m}}=\frac{\mathrm{m} \pi}{\mathrm{L}_{\mathrm{x}}} \\
\gamma_{\mathrm{n}}=\frac{\mathrm{n} \pi}{\mathrm{L}_{\mathrm{y}}}
\end{gathered}
$$

The modal amplitudes of excitation of the blade caused by centralized piezoelectric actuators are given by Eq. (6). The coefficient $\mathrm{C}_{0}$ is given by Eq. (7), with parameters K and P given by Eq. (8) and Eq. (9), respectively. The modal numbers plate $\gamma_{m}$ and $\gamma_{n}$ are given by Eq. (10) and Eq. (11), respectively.

The Rayleigh integral is a conceptual approach used to calculate the sound field radiated by a vibrating surface.

$$
\begin{aligned}
I_{m} & =\int_{0}^{L_{x}} e^{i(k x \operatorname{sen} \theta \cos \phi)} \operatorname{sen}\left(\frac{m \pi}{L_{x}} x\right) d x \\
I_{n} & =\int_{0}^{L_{y}} e^{i(k x \operatorname{sen} \theta \cos \phi)} \operatorname{sen}\left(\frac{n \pi}{L_{y}} x\right) d y
\end{aligned}
$$

The functions derived from the Rayleigh integral, $I_{m}$ and $I_{n}$, are given by Eq. (12) and Eq. (13), respectively.

The acoustic performance is given by transmission loss parameter, defined as the logarithm ratio of the incident acoustic energy and the total acoustic energy.

$$
\begin{gathered}
\mathrm{PT}=10 \log _{10}\left(\frac{\Pi_{\mathrm{i}}}{\Pi_{\mathrm{t}}}\right) \\
\Pi_{\mathrm{i}}=\mathrm{P}_{\mathrm{i}}^{2} \mathrm{~L}_{\mathrm{x}} \mathrm{L}_{\mathrm{y}} \frac{\cos \theta_{\mathrm{i}}}{2 \rho \mathrm{c}} \\
\Pi_{t}=\frac{\Phi R^{4}}{2 \rho c}
\end{gathered}
$$

$\Phi=\frac{1}{\mathrm{R}^{2}} \int_{\mathrm{s}}\left|\mathrm{p}_{\mathrm{t}}\right|^{2} \mathrm{ds}$

$$
=\frac{1}{\mathrm{R}^{2}} \int_{0}^{2 \pi} \int_{0}^{\frac{\pi}{2}}\left|\mathrm{p}_{\mathrm{t}}\right|^{2} \operatorname{sen} \theta \mathrm{d} \theta \mathrm{d} \varphi
$$

The transmission loss of the blade with piezoelectric actuators, as given by Eq. (14), and the values of the acoustic power incident $\left(\Pi_{i}\right)$ and radiated acoustic power $\left(\Pi_{t}\right)$ are obtained by Eq. (15) and Eq. (16), respectively, with the objective function $\Phi$ defined by Eq. (17).

\section{Acoustic Performance}

The total radiated acoustic pressure of the blades given can be obtained by the superposition principle, i.e, by the action of plate instrumented with piezoelectric actuators and the primary source.

$$
\begin{aligned}
p t(r, \theta, \phi)= & K \sum_{m=1}^{\infty} \sum_{n=1}^{\infty} W_{m n, p z t} I_{m} I_{n} \\
& +K \sum_{m=1}^{\infty} \sum_{n=1}^{\infty} W_{m n} I_{m} I_{n}
\end{aligned}
$$

The total radiated acoustic pressure acoustic active louvre $\mathrm{p}_{\mathrm{t}}$ is given by Eq.(18), in $[\mathrm{Pa}] ; \mathrm{W}_{\mathrm{mn}}$ are the modal amplitudes of the plate, [dimensionless]; $\mathrm{W}_{\mathrm{mn}}$, PZT are the modal amplitudes an instrumented with piezoelectric actuators plate, [dimensionless] $\mathrm{I}_{\mathrm{m}}$; $I_{n}$ the integral functions are derived from Rayleigh; $\mathrm{m}, \mathrm{n}$ are modal indices.

\section{Power requirements}

Conservative estimates of the maximum power consumption of piezoelectric actuators can be determined disregarding the dynamic between the actuator and the structure for optimal control situations.

$$
\mathrm{P}_{\max }=\frac{1}{2} \omega \mathrm{V}_{\max }^{2} \sum_{\mathrm{i}=1}^{\mathrm{n}}\left(\varepsilon_{33}-\mathrm{d}_{31}^{2} \mathrm{E}_{\mathrm{pe}}\right) \frac{\mathrm{wL}}{\mathrm{t}}
$$

According to Leo (2007), the maximum power required for each blade shutter can be obtained by Eq. (19), where Pmax is the maximum power required, [W]; Vmax is the coercive field of the actuator in [V]; is the dielectric constant $(\mathrm{nF} / \mathrm{m})$; $\mathrm{w}$ is the thickness of the actuator [m]; $l$ is the length of the actuator, [m]; $n$ is the number of actuators.

\section{Optimization}

Two-dimensional modeling of the excitation shutter blade by piezoelectric actuators was 
performed by applying a force in the $\mathrm{x}$ and $\mathrm{y}$ directions initially located at the point of maximum modal strain. The optimal placement of actuators was defined from analytical modeling of active shutter, using the pseudo-random method of genetic algorithms MATLAB ${ }^{\circledR}$. The objective function consists in minimizing the energy transmitted by the vibration of blades instrumented with piezoelectric actuators, excited for the frequency range 100-3150 Hz. The force applied to the blade of the louvre is the blocking force of the actuator.

$$
\mathrm{F}_{\mathrm{a}}=\mathrm{td}_{31} \mathrm{E}_{\mathrm{pe}} \mathrm{V}
$$

According to Brennan and McGowan [s.d], the blocking force of the actuator is given by Eq. (20), where $d_{31}$ is the piezoelectric constant in $[\mathrm{mV}]$; $t$ is the thickness of the actuator [m]; $\mathrm{E}_{\mathrm{pe}}$ is the modulus of elasticity of the actuator in $\left[\mathrm{N} / \mathrm{m}^{2}\right]$; $\mathrm{V}$ is the voltage applied to the actuator in [V].

For optimum control conditions, the external force must be less than or equal to the force actuator lock, according Fig. 2.

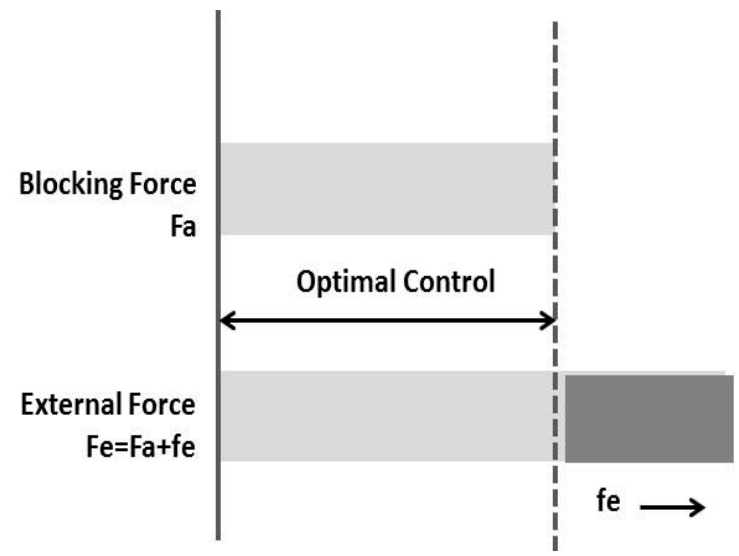

Figure 2. Actuator`s force diagram.

Considering a condition of perfectly controlled structure, the displacement of the structure coupled with actuators should be null. Otherwise, additional forces are introduced contributing to the reduction of the total admittance of the actuator. The optimization technique using pseudo -random method of genetic algorithms in MATLAB ${ }^{\circledR}$ was adopted to determine the amplitude and phase of the blocking force of the actuator integrated to the harmonic solution performed by the finite element method in ANSYS ${ }^{\circledR}$. In this case, the goal of active control function was to minimize the displacement of the shutter blades, whose harmonic analyzes were performed for the frequency range $100-500 \mathrm{~Hz}$, with a resolution of $20 \mathrm{~Hz}$ We thus main result, the deformations suffered by the blades. The acoustic attenuation of active shutter is obtained by performing new harmonic analysis considering the application of the blocking force of the optimized actuator. From the blocking force of the actuator can be calculated by Eq.(20) the thickness of the piezoelectric element and hence analytically determining the performance of active shutters in terms of loss by transmission, index of overall noise reduction and energy consumption.

\section{RESULTS}

The application of force on the blade intended to simulate the destructive interference of the waves, i.e, the emission of a signal of the same amplitude and opposite to the signal emitted by a primary source whose phase noise is intended to override. Thus, in Fig. 3 shows the magnitude of the forces applied to the shutter blade obtained by the optimization process. The real part refers to the force amplitude and the imaginary part refers to the stage to cancel the noise radiated by the vibration of the blade. We observed amplitudes less than $1 \mathrm{~N}$ for the control of blade vibration modes below $500 \mathrm{~Hz}$ for the purpose of active noise control. Negative amplitudes are observed for the blocking force of the actuator to 100 and $120 \mathrm{~Hz}$; as well as intervals [180; $320] \mathrm{Hz}$ and $[400 ; 480] \mathrm{Hz}$ and negative phases to the intervals [120;220] $\mathrm{Hz}$ and [340;420] $\mathrm{Hz}$ Note also that, with some exceptions, there is a tendency for the amplitude and phase of the blocking force of the actuator display opposite signs across the frequency spectrum analyzed.

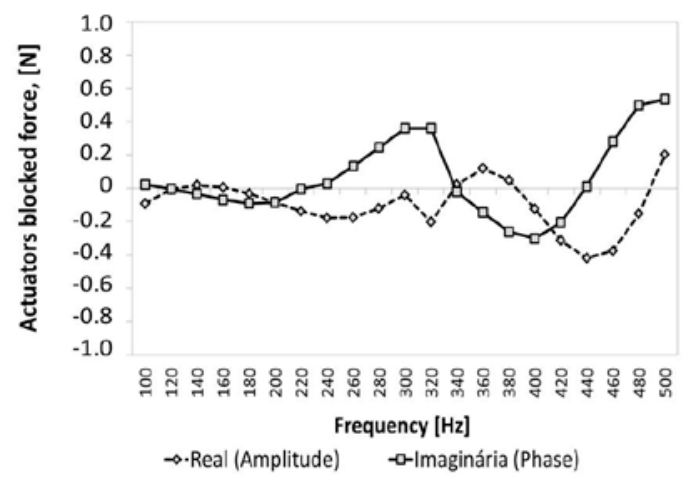

Figure 3. Blocking force actuator for active noise control applied to acoustic louvre.

The relation between the energy requirements for operating the louvre and its active acoustic performance in terms of weighted sound reduction index is shown in Fig. 4 to the vibration modes for a given value of $m$, there is a tendency to increase the acoustic performance when the value of $n$ increases. However, it is not necessarily observed improvements in acoustical performance with increasing modal density control. The active control of only the frequencies below $500 \mathrm{~Hz}$, i.e., vibration mode (4.1) has a weighted sound reduction index similar to the values obtained for the control of the natural frequencies up to $4620 \mathrm{~Hz}$, that is, the vibration mode (5.5). Moreover, this increase in modal density of active control in addition to not 
contribute to increase the acoustic performance of active louvre, contributes to the increased power consumption of the device, since we have powers about 10 times higher than those observed for control only frequencies below $500 \mathrm{~Hz}$ thus , acoustic energy requirements and justify the proposal of active louvres as a hybrid device, i.e, active noise control for frequencies below $500 \mathrm{~Hz}$ and passive control using sound absorption materials for frequencies between 500 and $4000 \mathrm{~Hz}$.

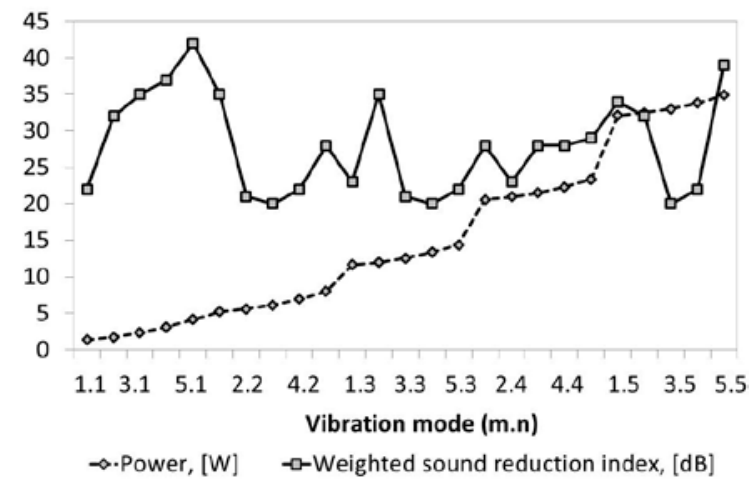

Figure 4. Relationship between energy and acoustic performance of active louvres.

\section{CONCLUSION}

The modeling procedure of active acoustic louvres involving the simulation process using analytical and numerical methods associated with optimization techniques allowed the determination of optimum parameters for the design of active louvres.

The active control of only the frequencies below $500 \mathrm{~Hz}$ has a weighted sound reduction index similar to the values obtained for the control of the natural frequencies up to $4620 \mathrm{~Hz}$. Thus, the optimized device configuration shows weighted sound reduction index of $37 \mathrm{~dB}$ and a low power consumption of $5 \mathrm{~W}$. Despite the active louvres trends already present at a low energy consumption compared to mechanical air conditioning systems, we intend to further analyze alternative technology combining piezoelectric materials with passive electrical circuits, called shunt circuits. This type of solution would allow energy self-sufficiency of the device since the energy consumed to operate the actuators would be generated by the vibration of the blades.

\section{ACKNOWLEDGEMENTS}

We would like to thank the funding agencies CAPES, CNPQ and FAPEMIG for their financial support.

\section{REFERENCES}

Araujo, B. C. D., 2010, Proposta de Elemento Vazado Acústico, Doctoral Thesis, Faculdade de
Arquitetura e Urbanismo - USP, São Paulo, SP. (in Portuguese)

Brennan, M. C., and Mc Gowan, A. R., 1997, Piezoelectric Power Requirements for Active Vibration Control, NASA Langley Technical Report Server, pp. 1-10.

Field, C. D, and Fricke, F. R., 1998, Theory and Applications of Quarter-Wave Resonators: a Prelude to their use for Attenuating Noise Entering Buildings Through Ventilation Openings, Applied Acoustics, Vol. 53, No. 1-3, pp. 117-132.

Leo, D., 2007, Engineering Analysis of Smart Material Systems, John Wiley \& Sons.

Naticchia, B., and Carbonari, A., 2007, Feasibility Analysis of an Active Technology to Improve Acoustic Comfort in Buildings, Building and Environment, Vol. 42, pp. 2785-2796.

Oiticica, M. L. G. R., 2010, Desempenho Acústico de Diferentes Tipologias de Peitoril Ventilado, Doctoral Thesis, Faculdade de Engenharia Civil, Arquitetura e Urbanismo, UNICAMP, Campinas, SP. (in Portuguese)

Salis, M. H. F., Oldham, D. J., and Sharples, S., 2002, Noise Control Strategies for Naturally Ventilated Buildings, Building and Environment, Vol. 37, pp. 471-484.

Viegas, M. N., 2009, Arquitetura e Acústica Bioclimática: Estudo de Fachadas Visando ao Controle do Ruído Urbano e ao Conforto Térmico nas Edificações em Clima Quente Úmido, Doctoral Thesis, Faculdade de Engenharia Mecânica, UFRJ, Rio de Janeiro, RJ. (in Portuguese)

Viveiros, E. B., and Gibbs, B. M., 2003, An Image Model for Predicting the Field Performance of Acoustic Louvres from Impulse Measurements, Applied Acoustics, Vol. 64. pp. 713-730. 